\title{
Chapter 11 \\ Effects of Urban Green Space on Environmental Health, Equity and Resilience
}

\author{
Matthias Braubach, Andrey Egorov, Pierpaolo Mudu, Tanja Wolf, \\ Catharine Ward Thompson, and Marco Martuzzi
}

\begin{abstract}
Modern urban life style is associated with chronic stress, insufficient physical activity and exposure to anthropogenic environmental hazards. Urban green space, such as parks, playgrounds, and residential greenery, can promote mental and physical health and reduce morbidity and mortality in urban residents by providing psychological relaxation and stress alleviation, stimulating social cohesion, supporting physical activity, and reducing exposure to air pollutants, noise and excessive heat.

This chapter summarizes the pathways that link green spaces to health and wellbeing, and discusses available evidence of specific beneficial effects such as improved mental health, reduced risks of cardiovascular disease, obesity, diabetes and death, and improved pregnancy outcomes

Specific attention is given to benefits of urban green space for disadvantaged groups and their impacts on health equity. Potential health risks associated with urban green spaces are also discussed along with approaches to reducing or eliminating these risks through proper design and maintenance of green spaces.
\end{abstract}

Keywords Urban health - Environment - Environmental health - Resilience • Health $\bullet$ Public health $\bullet$ Health impacts $\bullet$ Health impact mechanisms $\bullet$ Relaxation • Restoration • Immune system $\bullet$ Physical activity $\bullet$ Obesity $\bullet$ Diabetes $\bullet$ Mental health $\bullet$ Morbidity $\bullet$ Mortality $\bullet$ Side effects $\bullet$ Prevention $\bullet$ Equity $\bullet$ Social cohesion - Social capital $\bullet$ Vulnerable groups $\bullet$ Urban planning $\bullet$ Public spaces $\bullet$ Green spaces - Evidence review $\bullet$ Epidemiological studies

M. Braubach $(\triangle) \bullet$ P. Mudu $\bullet$ T. Wolf $\bullet$ M. Martuzzi

European Centre for Environment and Health, WHO Regional Office for Europe,

Bonn, Germany

e-mail: braubachm@who.int; mudup@who.int; wolft@who.int; martuzzim@who.int
A. Egorov
Office of Research and Development, U.S. Environmental Protection Agency,
Chapel Hill, North Carolina, USA
e-mail: egorov.andrey@epa.gov
C. Ward Thompson
OPENspace Research Centre, University of Edinburgh, Edinburgh, UK
e-mail: c.ward-thompson@ed.ac.uk 


\subsection{Introduction}

The previous chapters have summarized evidence that nature-based solutions to the common problems of urbanization can provide ecosystem services and enhance climate change adaptation in urban settings. Nature-based solutions can also improve the health and well-being of urban residents through salutogenic elements in the urban environment facilitating psychological relaxation and stress relief, providing enhanced opportunities for physical activity and reducing exposure to noise, air pollution and excessive heat. Many epidemiological studies have demonstrated various positive health effects of urban green spaces, including reduced depression and improved mental health, reduced cardiovascular morbidity and mortality, improved pregnancy outcomes and reduced rates of obesity and diabetes (reviewed by WHO Regional Office for Europe 2016). Thus, providing urban green space is a nature-based solution with a variety of known health and well-being benefits. While urban green space can also be associated with health hazards, such as increased exposure to allergenic pollen, infections transmitted by arthropod vectors such as ticks or mosquitoes, and risk of injuries, potential detrimental effects can be eliminated or minimized through proper design, maintenance and operation of green space (Lõhmus and Balbus 2015).

It is important to note that disadvantaged population groups often live in neighbourhoods with reduced availability of green space. Studies have shown that socioeconomically disadvantaged individuals tend to benefit the most from improved access to urban greenery. Thus, reducing socioeconomic disparities in the availability of urban green space may help to reduce inequalities in health related to income, minority status, disability and other socioeconomic and demographic factors (Allen and Balfour 2014).

Providing equitable access to green space is an important goal of health-oriented urban policies. Targets related to improving access to green space have been included in international agreements and declarations. The Health2020 strategy calls for the development of resilient and supportive local environments in the WHO European Region (WHO Regional Office for Europe 2013). The Parma Declaration on Environment and Health adopted by the Member States of the WHO European Region includes the commitment "...to provide each child by 2020 with access to health and safe environments and settings of daily life in which they can walk and cycle to kindergartens and schools, and to green spaces in which to play and undertake physical activity" (WHO Regional Office for Europe 2010). An urban environment assessment performed by the European Environment Agency concluded that urban green space can buffer environmental hazards and contribute to health, stimulating EU Member States to develop national policy targets (European Environment Agency 2015). The Sustainable Development Goals (United Nations 2016) adopted by the United Nations in 2015 include the following goal: "By 2030, provide universal access to safe, inclusive and accessible, green and public spaces, particularly for women and children, older persons and persons with disabilities" (Target 11.7). 
This section discusses pathways leading to health benefits, and summarizes existing epidemiological evidence of public health benefits of urban green space, with a particular focus on equity issues. In this context, it is important to note that different studies have used varying definitions of urban green space. Therefore, for the purpose of this chapter, the term "urban green space" is used inclusively to mean any type of greenery in urban settings, without distinctions regarding size, quality, and public or private ownership.

\subsection{Pathways Linking Urban Green Space with Health and Well-Being}

The pathways leading to beneficial health effects of green space are diverse and complex. Various models have been formulated to explain the relationship between green space and health. Hartig et al. (2014) suggested four interacting pathways through which green space can affect health and well-being: (1) improved air quality, (2) enhanced physical activity, (3) stress compensation and (4) greater social cohesion. Lachowycz and Jones (2013) proposed physical activity, engagement with nature, relaxation, and social interactions as major pathways to health. Villanueva et al. (2015) argued that urban green spaces mitigate the urban heat island effect providing protection from heat-related health hazards, improve social capital and cohesion, and enhance physical activity. In addition to the pathways outlined above, Kuo (2015) suggested exposure to natural microbes and enhanced immune system functioning as a major pathway linking nature and health. Relative contributions of different pathways as well as their potential synergistic effects remain to be elucidated. Meanwhile, insufficient knowledge of underlying causal pathways to health outcomes and the complex modifying social and environmental factors hinders the implementation of focused policy interventions. An in-depth interdisciplinary research is needed to close these knowledge gaps in the area of urban environment and health (Shanahan et al. 2015).

This chapter focuses on the discussion of, and the health impacts related to (1) improved relaxation and restoration, (2) improved functioning of the immune system, (3) enhanced physical activity and (4) improved social capital. Health and societal benefits related to ecosystem services (e.g. reduction of air pollution, noise, exposure to excessive heat) will be discussed in the next chapter.

\subsubsection{Improved Relaxation and Restoration}

The evidence of health benefits due to mental restoration and relaxation from having contact with nature and green space is well documented (Hartig et al. 2014; Hartig 2007). It has been suggested that contacts with nature (e.g. views of green space) can trigger positive effects for persons with high stress levels by shifting 
them to a more positive emotional state (Ulrich 1983; Ulrich et al. 1991) and that stimuli in natural settings help to restore a sense of well-being in persons suffering mental fatigue (Kaplan 1995; Kaplan 2001).

Hartig et al. (2014) noted that "substantial evidence speaks to the potential benefits of contact with nature for avoiding health problems traceable to chronic stress and attentional fatigue", but also pointed out that most previously conducted studies demonstrated only short-term restorative benefits of one-off nature experiences. For example, a study in the United Kingdom used wearable sensors to demonstrate the effects of a short walk in a green space on brain activity that might be associated with enhanced relaxation and restoration (Aspinall et al. 2015). It was also shown that walking in natural environments produces stronger short-term cognitive benefits than walking in the residential urban environment (Gidlow et al. 2016a). Cortisol measures have demonstrated that gardening alleviated acute stress faster than reading (van den Berg and Custers 2011). It has also been demonstrated that exposure to green space reduces neural activity in the subgenual prefrontal cortex and alleviates depression symptoms (Bratman et al. 2015).

Recent studies have also provided evidence of chronic stress alleviation by green space. Using diurnal cortisol patterns was an innovative approach applied in the United Kingdom to demonstrate that exposure to green space reduced chronic stress in adults living in deprived urban neighbourhoods (Roe et al. 2013; Ward Thompson et al. 2012; Beil and Hanes 2013). Similar relationships between green space and stress reduction have been shown using hair cortisol as a biomarker of chronic stress (Honold et al. 2015; Gidlow et al. 2016b).

\subsubsection{Improved Functioning of the Immune System}

Kuo (2015) suggested a central role for enhanced immune functioning in the pathways between nature and health. Associations between visiting forests and beneficial immune responses, including expression of anti-cancer proteins, have been demonstrated in Japan ( $\mathrm{Li}$ et al. 2008). This suggests that immune systems benefit from direct exposure to natural environments or through contacts with certain factors in the green space. It has also been shown that children with the highest exposure to specific allergens or bacteria during their first year of life were least likely to have recurrent wheeze and allergic sensitization (Lynch et al. 2014). Living in residential areas with more street trees was shown to be associated with lower asthma prevalence (Lovasi et al. 2008). One hypothesized immunological pathway is exposure to commensal microorganisms in biodiverse natural environments (Rook 2013), which can play an immunoregulatory role. Studies have demonstrated that increased biodiversity in the environment around homes is linked with reduced risk of allergy (Ruokolainen et al. 2015; Hanski et al. 2012). Greater exposure to commensal microorganisms, especially in the early life, may lead to more diverse skin and gut microbiomes, and provide protection against allergy and autoimmunity 
(Kondrashova et al. 2013). It has also been suggested that the human microbiome associated with natural environmental may improve mental health (Logan 2015).

\subsubsection{Enhanced Physical Activity and Improved Fitness}

Physical activity has been shown to improve cardiovascular health, mental health, neurocognitive development, and general well-being and to prevent obesity, cancer, and osteoporosis (Owen et al. 2010). Providing attractive and accessible urban environments may encourage people to spend more time outdoors and facilitate physical activity (Bedimo-Rung et al. 2005). The quality of the urban green space and presence of specific amenities are important factors facilitating physical activity in older adults (Aspinall et al. 2010; Sugiyama and Ward Thompson 2008). For urban residents with mental health problems, physical activity in green space may be particularly therapeutic (Roe and Aspinall 2011). Other populations or subgroups may benefit, in a similar way, from green space that makes outdoor activity enjoyable and easy, and encourages less sedentary lifestyles.

Hartig et al. (2014) summarized available evidence for an association between green space and physical activity levels in three domains: work, active transport and leisure. While access to green spaces has been linked to active leisure, associations between greenness and active commuting (such as walking and cycling) are inconsistent because very green living environments can be highly car-dependent for transport (Bancroft et al. 2015).

Numerous studies in multiple countries have demonstrated that recreational walking, increased physical activity and reduced sedentary time were associated with access to, and use of green space in working age adults, children and senior citizens (Epstein et al. 2006; Kaczynski and Henderson 2007; Kaczynski et al. 2008; Sugiyama and Ward Thompson 2008; Cochrane et al. 2009; Almanza et al. 2012; Lachowycz et al. 2012; Astell-Burt et al. 2013; Schipperijn et al. 2013; Lachowycz and Jones 2014; Sugiyama et al. 2014; Gardsjord et al. 2014; James et al. 2015; Sallis et al. 2016).

Almanza et al. (2012) used satellite images and GPS and accelerometer data from children in several communities in California, the United States to demonstrate that increased residential greenness was positively associated with moderate to vigorous physical activity. Bjork et al. (2008) and De Jong et al. (2012), working in Sweden, found a positive association between access to high quality green space and higher levels of physical activity.

There is also accumulating evidence that physical activity in green space ("green exercise") is more restorative and beneficial for health than physical activity in nonnatural environments (Barton and Pretty 2010; Bodin and Hartig 2003). Mitchell's (2013) study of the Scottish population showed an association between physical activity in natural environments and reduced risk of poor mental health, while activity in other types of environment was not linked to the same health benefit. 


\subsubsection{Improved Social Capital and Cohesion}

Social relationships have a well-known protective effect on health and well-being, while social isolation is predictor of morbidity and mortality (Nieminen et al. 2010; Pantell et al. 2013; Yang et al. 2016). Green space can play an important role in fostering social interactions and promote a sense of community that is essential for social cohesion (Kim and Kaplan 2004) as well as for human health (Lengen and Kistemann 2012). Public urban green space has been shown to facilitate social networking and promote social inclusion in children and adolescents (Seeland et al. 2009; Ward Thompson et al. 2016). The quantity and the quality of greenery have been linked with improved social cohesion at the neighbourhood scale (de Vries et al. 2013) while shortage of green space has been associated with perception of loneliness and lack of social support (Maas et al. 2009a). However, the relationships between green space and social well-being are complex. Although observational studies have demonstrated positive effects on well-being, characterizing the underlying mechanisms remains a challenge (Hartig et al. 2014).

\subsection{Health Benefits of Green Space and Potential Health Risks}

This section summarizes the available epidemiological evidence of health benefits linked to green space through pathways which were discussed in the previous section. It is important to note that each pathway can lead to more than one health benefit, and that different pathways can also contribute to the same benefit. For example, cardiovascular benefits can be caused by enhanced physical activity, improved mental restoration leading to reduced chronic stress, and by reduced exposure to air pollution and noise.

\subsubsection{Improved Mental Health and Cognitive Function}

There is strong evidence of mental health benefits of urban green space (reviewed by de Vries 2010). Greater perceived neighbourhood greenness has been strongly associated with improved mental health (Sugiyama et al. 2008). Greater surrounding greenness has been linked to improved physical and mental health in all socioeconomic strata and in both sexes in Spain (Triguero-Mas et al. 2015). The associations were stronger for the surrounding greenness measured by the Normalized Difference Vegetation Index (NDVI) than for access to geographically distinct green spaces. Further analysis also demonstrated that this association was not mediated by physical activity. This suggests that psychological relaxation was an important contributing pathway to health. 
It was shown that individuals living in urban areas with more green space tend to have reduced level of stress and better well-being compared to those with poorer availability of green space (White et al. 2013). More greenery in the neighbourhood was linked to lower levels of depression, anxiety and stress (Beyer et al. 2014; Bratman et al. 2015; Reklaitiene et al. 2014; Pope et al. 2015); improved access to water bodies (blue spaces) has also been linked to enhanced mental well-being in city dwellers (Völker and Kistemann 2015). In a prospective study in the United Kingdom, moving to greener residential areas has been linked with persistent mental health improvements; the mechanisms leading to these improvements have not been elucidated (Alcock et al. 2014). While most studies relied on measures of green space availability as a proxy measure of exposure, a multicity study in Europe linked greater time spent in green spaces with improved self-reported health and vitality; the effects were consistent in all four study sites in Spain, Lithuania, The Netherlands and the United Kingdom suggesting that health benefits are independent of cultural and climatic contexts (Van den Berg et al. 2016).

A number of studies provided evidence that green spaces are especially beneficial for certain subpopulations or for disadvantaged groups. Moving to an area with better access to green space characterized as "serene" has been linked to improved mental health in a representative sample of adult Swedish women (van den Bosch et al. 2015). There is also some evidence for the beneficial effects of green space on mental health and cognitive development in children. A study in Lithuania found mental health benefits in children of mothers with low education level while the results for children of highly educated mothers were inconsistent (Balseviciene et al. 2014).

Increased usage of green and blue spaces, and greater residential greenness have been associated with improved behavioural development and reduced rate of Attention Deficit Hyperactivity Disorder (ADHD) in children (Amoly et al. 2014). Higher levels of greenness at home and school were associated with improved cognitive development (i.e., better progress in working memory and reduced inattentiveness) in schoolchildren in an observational study in Spain (Dadvand et al. 2015). A number of other studies have similarly demonstrated the positive impact of green space exposure on ADHD and related cognitive symptoms (Faber Taylor and Kuo 2011; van den Berg and van den Berg 2011; Markevych et al. 2014). There is also evidence of therapeutic benefits of engaging people with autism with nature (reviewed by Faber Taylor and Kuo 2006).

\subsubsection{Reduced Cardiovascular Morbidity and Mortality}

Improved access to green space was linked to a reduced detrimental impact of income deprivation on cardiovascular mortality (Mitchell and Popham 2008) while a prospective study in Lithuania demonstrated that greater distance to green space was associated with increased risk of cardiovascular disease (Tamosiunas et al. 2014). Many studies have also provided evidence that the risk of cardiovascular mortality is lower in areas with higher residential greenness (reviewed by Gascon et al. 2016). 
A randomized intervention study in Lithuania by Grazuleviciene et al. (2015b) demonstrated that walking in a park had a stronger effect on reducing diastolic blood pressure than similar amount of walking along a busy urban street, suggesting a potential biological mechanism of long-term clinical benefits. An observational study in Australia demonstrated that a greater variability in landscape combining trees and open green space was associated with reduced risk of cardiovascular disease and stroke (Pereira et al. 2012). The authors hypothesized that variability in neighbourhood greenness reflects two factors promoting physical activity - an aesthetically pleasing natural environment and access to urban destinations.

\subsubsection{Reduced Prevalence of Obesity and Type 2 Diabetes}

A systematic review of 60 studies from the United States, Canada, Australia, New Zealand and Europe on the relationships between green space and obesity indicators found that the majority $(68 \%)$ of papers showed that green space is associated with reduced obesity; the relationships could be modified by age and socioeconomic status (Lachowycz and Jones 2011). A more recent study in Spain confirmed these conclusions and showed that living in greener residential areas and living in closer proximity to forests was linked with less sedentary time and reduced risks of overweight and obesity in children (Dadvand et al. 2014a).

Furthermore, there is some evidence that using green space for gardening may influence physical activity, improve social well-being and encourage eating healthy food, thereby reducing obesity. A pilot intervention study using community gardening and education in nutrition in a southern state in the United States found that $17 \%$ of obese and overweight children had improved their BMI classification by the end of the seven-week-long programme (Castro et al. 2013).

It is well-known that type 2 diabetes mellitus can be prevented by reducing obesity and improving physical activity. Exposure to air pollution is another risk factor for systemic diseases including cardiovascular disease and type 2 diabetes acting through oxidative stress and systemic inflammation mechanisms. Cross-sectional observational studies in The Netherlands, Australia and the United Kingdom demonstrated statistically significant associations between neighbourhood greenness and reduced odds of having type 2 diabetes mellitus (Astell-Burt et al. 2014; Maas et al. 2009b; Bodicoat et al. 2014). A study in Germany demonstrated an inverse association between neighbourhood greenness (measured by NDVI) and insulin resistance in adolescents (Thiering et al. 2016). The observed protective effect of green space was partially explained by a reduced exposure to traffic-related nitrogen dioxide.

\subsubsection{Improved Pregnancy Outcomes}

In a systematic review, Dzhambov et al. (2014) summarized evidence showing that residential access to green space is associated with reduced risk of low birth weight. Low birth weight is one of main predictors of neonatal and infant mortality, as well 
as long-term adverse effects in childhood and beyond. More recent studies (AgayShay et al. 2014; Markevych et al. 2014; Dadvand et al. 2014b) provided further evidence of beneficial effects of green space on birth weight. A larger distance to a city park was also linked with increased risk of preterm birth and with reduced gestational age at birth (Grazuleviciene et al. 2015a), while improved availability of green space was linked with reduced risk of preterm births (Laurent et al. 2013).

\subsubsection{Reduced Mortality and Increased Life Span}

A recent meta-analysis of previously conducted studies demonstrated that increased availability of green space is linked with a reduction of mortality (reviewed by Gascon et al. 2016).

For example, a study in Japan has shown that the five-year survival rate in elderly individuals was positively associated with having access to green space suitable for taking a stroll and with parks and tree-lined streets near the residence (Takano et al. 2002). Another study of pre-retirement age population in England showed that a greater amount of green space in the neighbourhood was associated with reduced all-cause mortality (Mitchell and Popham 2008). The study reinforced earlier findings based on the 2001 census population of England, which found that a higher proportion of green space in an area was associated with better self-reported health (Mitchell and Popham 2007).

A longitudinal study in Canada found that increased residential green space was associated with a reduction in mortality (Villeneuve et al. 2012); the strongest effect was on mortality from respiratory diseases. In Spain, Xu et al. (2013) showed that perceived greater neighbourhood greenness was associated with reduced mortality risk during heat waves due to an urban heat island mitigating effect of green space.

In the United States, residential proximity to green space has been associated with a reduced risk of stroke mortality (Hu et al. 2008) and with higher survival rates after ischemic stroke (Wilker et al. 2014). In contrast to the above findings, Richardson et al. (2012) did not find an association between availability of green space and overall mortality in the 49 largest cities in the United States. The authors suggested this might be due to the sprawling nature of these cities and high levels of car dependency.

\subsubsection{Potential Adverse Health Effects}

Greater availability and enhanced use of green space may also be associated with exposure to health hazards (reviewed by Lõhmus and Balbus 2015), although the evidence on adverse health impacts of urban green space is based on fewer studies and it is less consistent than the evidence of health benefits. 
Potential adverse health effects are associated with increased exposure to pesticides, allergenic pollen, arthropod vectors of infectious diseases, infectious agents in soils contaminated with animal faeces, and increased risk of injuries (reviewed by WHO Regional Office for Europe 2016). It should be noted, however, that associations between green space and allergy are inconsistent, with research in some areas showing that green space is linked to an increased risk of allergy, while similar investigations in other geographic areas show strong protective effects (Fuertes et al. 2016). The latter are corroborated by studies that found associations between increased biodiversity around homes and reduced atopic sensitization (Ruokolainen et al. 2015; Hanski et al. 2012). This demonstrates the need for more in-depth studies quantifying exposure to pollen, addressing potential confounding and characterizing mechanisms of age-specific adverse and beneficial health effects. It should also be noted that activities involving risk-taking and exploratory behaviour are important for normal development of children and that environments supportive of risky play promote increased play time, social interactions, creativity and resilience (Brussoni et al. 2015).

Most potential detrimental effects can be eliminated or minimized through proper design, maintenance and operation of green space (Lõhmus and Balbus 2015). Thus, the design of green spaces such as of parks, green trails and playgrounds should take in account these potential side effects and take measures to minimize the risk of allergens or serious injuries.

\subsection{Benefits in Disadvantaged Groups and Reduction of Health Inequality}

Green space is not equally available or accessible to all population groups (WHO Regional Office for Europe 2012), with low-income communities often having less green space or being exposed to poorly maintained, vandalized or unsafe green areas. Socioeconomic inequalities in access to green space and resulting health benefits may therefore contribute to inequalities in health (The Marmot Review 2010).

It has been suggested that addressing the 'upstream' determinants of health - e.g. by making changes to the built environment - has the potential to reduce populationwide health inequalities; especially the availability of good quality green space across the social gradient is considered essential to tackle health inequalities (Allen and Balfour 2014). While the equity aspects of access to quality green space are discussed in detail in the following chapter by Kabisch et al., this section addresses potential equity issues regarding the health benefits of green space.

There is accumulating evidence showing that urban green space may be 'equigenic' (Mitchell et al. 2015), i.e. that the health benefits linked with access to green space may be strongest among the disadvantaged groups. The study found socioeconomic inequalities in mental health to be substantially lower amongst people reporting good access to recreational/green areas compared to those with poorer access. Other studies showed that populations exposed to the greenest environments 
had the lowest level of health inequality related to income deprivation (Mitchell and Popham 2008; Lachowycz and Jones 2014). Pope et al. (2015) identified statistically significant associations between reported access to, and better quality of, green space and reduced psychological distress in a deprived urban population in the US. In a large European epidemiological study, Mitchell et al. (2015) found that socioeconomic inequality in mental well-being was $40 \%$ narrower among respondents reporting good access to green space, compared with those with poorer access.

Improving the availability of good quality green space in disadvantaged urban neighbourhoods contributes to addressing health inequalities (Allen and Balfour 2014). For example, improvements in access to woodland green space near deprived urban communities in Scotland, United Kingdom had a positive impact on green space use and may have contributed to improvements in activity levels and perceived quality of life (Ward Thompson et al. 2013).

Sreetheran and van den Bosch (2014), in a systematic review of English language literature, found that being an ethnic minority and living in low-income neighbourhoods affects feelings of insecurity in urban green space. Research findings also suggest that, in some settings, beneficial effects of exposure to green space on birth weight may be pronounced only in the lowest socioeconomic position group (Dadvand et al. 2012) or in specific cultural or ethnic groups (Dadvand et al. 2014b). A French study indicated that both greenness level and socioeconomic deprivation partially explained the distribution of neonatal mortality (KihalTalantikite et al. 2013). Reducing barriers to the use of green space and taking measures to facilitate health-beneficial behaviours is likely to be an effective and far reaching strategy for public health improvement (Public Health England 2014). A WHO report on addressing inequities in overweight and obesity calls for urban planning policies to set minimum green space requirements in residential developments (WHO Regional Office for Europe 2014).

\subsection{Conclusion}

The available evidence summarized in this chapter suggests that potential causal pathways leading to public health benefits of urban green spaces include psychological relaxation and stress reduction, improved social cohesion and psychological attachment to the home area, immune system benefits and enhanced physical activity. Green space can also provide ecosystem services associated with reduced exposures to noise, air pollution and excessive heat, which are discussed in the following chapter.

The evidence for health benefits due to relaxation, stress reduction and other psychological effects appears to be very consistent. Many studies have demonstrated associations between greenery in close proximity to residence and health benefits suggesting that being in green space can produce health benefits regardless of the level of physical activity. These health benefits depend on the overall greenness of residential areas and can be provided by adequate urban planning mecha- 
nisms. The health benefits mediated by physical activity in green spaces depend on the availability of public green spaces suitable for active leisure and physical play. Green space can also contribute to the reduction of environmental and health inequalities by providing all population groups with equal opportunities to engage in and benefit from natural environments, and with equal ecosystem services, such as buffering of air pollution and noise.

In general, the health benefits of urban green space outweigh its potential detrimental effects, such as allergies to pollen, infections and injuries. Most negative effects are typically associated with poorly designed or poorly maintained green space; they can be reduced or prevented by proper planning, design and maintenance of urban green space (e.g. planting non-allergenic species, controlling disease vectors, improving safety of playgrounds). Measuring the availability, accessibility and quality of green space, and monitoring green space usage by specific population groups are essential steps for providing information in support of evidence-based targeted interventions. Such interventions will include measures that aim to remove barriers to green space utilization, and enhance their utilization by specific population groups, such as children, elderly, working age adults, pregnant women, cultural and ethnic minorities, and individuals with mental illness, cognitive impairments or physical limitations. Examples of such measures can include the provision of greenery in deprived neighbourhoods, physical interventions to enhance access and use of urban green space (such as attractive and welcoming entrances or well-drained and paved footpaths and benches), the regular provision of attractive, nature-based play grounds, and improving safety in urban parks. Improving the availability of green spaces in under-served and socioeconomically disadvantaged communities may help to reduce health inequalities in urban populations.

In addition to the documented health benefits described in this chapter, urban green space may also provide important economic and ecological co-benefits such as reduction of fossil fuel usage through enhanced use of cycling and walking and wildlife habitat supporting biodiversity in urbanized areas. Overall, cities that build and maintain well-connected, attractive green spaces are likely to have healthier, happier and more productive citizens with fewer demands for health services.

Developing and applying harmonized approaches to measuring green space, and producing consistent and comparable data on many cities is essential to enable local planners and policy-makers to assess the need for improvement, and to identify specific areas where green space interventions are warranted (WHO Regional Office for Europe 2016). A review of urban green space interventions has been carried out by WHO to assess environmental and health outcomes of urban green space actions and to inform local practitioners about the aspects to consider when planning green space interventions (WHO Regional Office for Europe 2017).

Disclaimer The views expressed in this manuscript are those of the individual authors and do not necessarily reflect the views and policies of the U.S. EPA. Mention of trade names or commercial products does not constitute endorsement or recommendation for use. 


\section{References}

Agay-Shay K, Peled A, Crespo AV, Peretz C, Amitai Y, Linn S, Friger M, Nieuwenhuijsen MJ (2014) Green spaces and adverse pregnancy outcomes. Occup Environ Med 71:562-569

Alcock I, White MP, Wheeler BW, Fleming LE, Depledge MH (2014) Longitudinal effects on mental health of moving to greener and less green urban areas. Environ Sci Technol 48:1247-1255

Allen J, Balfour R (2014) Natural solutions for tackling health inequalities, UCL Institute of Health Equity. http://www.instituteofhealthequity.org/projects/natural-solutions-to-tacklinghealth-inequalities. Accessed 13 May 2016

Almanza E, Jerrett M, Dunton G, Seto E, Ann Pentz M (2012) A study of community design, greenness, and physical activity in children using satellite, GPS and accelerometer data. Health Place 18:46-54

Amoly E, Dadvand P, Forns J, Lopez-Vicente M, Basagana X, Julvez J, Alvarez-Pedrerol M, Nieuwenhuijsen MJ, Sunyer J (2014) Green and blue spaces and behavioral development in Barcelona schoolchildren: the BREATHE project. Environ Health Perspect 122:1351-1358

Aspinall PA, Thompson CW, Alves S, Sugiyama T, Brice R, Vickers A (2010) Preference and relative importance for environmental attributes of neighbourhood open space in older people. Environ Plann B Plann Des 37:1022-1039

Aspinall P, Mavros P, Coyne R, Roe J (2015) The urban brain: analysing outdoor physical activity with mobile EEG. Br J Sports Med 49:272-276

Astell-Burt T, Feng X, Kolt GS (2013) Does access to neighbourhood green space promote a healthy duration of sleep? Novel findings from a cross-sectional study of 259319 Australians. Br Med J Open 3(8):e003094

Astell-Burt T, Feng X, Kolt GS (2014) Is neighborhood green space associated with a lower risk of type 2 diabetes? Evidence from 267,072 Australians. Diabetes Care 37:197-201

Balseviciene B, Sinkariova L, Grazuleviciene R, Andrusaityte S, Uzdanaviciute I, Dedele A, Nieuwenhuijsen M (2014) Impact of residential greenness on preschool children's emotional and behavioral problems. Int J Environ Res Public Health 11:6757

Bancroft C, Joshi S, Rundle A, Hutson M, Chong C, Weiss CC et al (2015) Association of Proximity and Density of parks and objectively measured physical activity in the United States: a systematic review. Soc Sci Med 138:22-30

Barton J, Pretty J (2010) What is the best dose of nature and green exercise for improving mental health? A multi-study analysis. Environ Sci Technol 44:3947-3955

Bedimo-Rung AL, Mowen AJ, Cohen DA (2005) The significance of parks to physical activity and public health: a conceptual model. Am J Prev Med 28:159-168

Beil K, Hanes D (2013) The influence of urban natural and built environments on physiological and psychological measures of stress-a pilot study. Int J Environ Res Public Health 10:1250-1267

Beyer KM, Kaltenbach A, Szabo A, Bogar S, Nieto FJ, Malecki KM (2014) Exposure to neighborhood green space and mental health: evidence from the survey of the health of Wisconsin. Int J Environ Res Public Health 11:3453-3472

Bjork J, Albin M, Grahn P, Jacobsson H, Ardo J, Wadbro J, Ostergren P-O, Skarback E (2008) Recreational values of the natural environment in relation to neighbourhood satisfaction, physical activity, obesity and wellbeing. J Epidemiol Community Health 62(4):e2-e2

Bodicoat DH, O'Donovan G, Dalton AM, Gray LJ, Yates T, Edwardson C, Hill S, Webb DR, Khunti K, Davies MJ, Jones AP (2014) The association between neighbourhood greenspace and type 2 diabetes in a large cross-sectional study. Br Med J Open 4:e06076

Bodin M, Hartig T (2003) Does the outdoor environment matter for psychological restoration gained through running? Psychol Sport Exerc 4:141-153

Bratman GN, Hamilton JP, Hahn KS, Daily GC, Gross JJ (2015) Nature experience reduces rumination and subgenual prefrontal cortex activation. Proc Natl Acad Sci U S A 112:8567-8572 
Brussoni M, Gibbons R, Gray C, Ishikawa T, Sandseter EB, Bienenstock A, Chabot G, Fuselli P, Herrington S, Janssen I, Pickett W, Power M, Stanger N, Sampson M, Tremblay MS (2015) What is the relationship between risky outdoor play and health in children? A systematic review. Int J Environ Res Public Health 12(6):6423-6454

Castro DC, Samuels M, Harman AE (2013) Growing healthy kids: a community garden-based obesity prevention program. Am J Prev Med 44:S193-S199

Cochrane T, Davey RC, Gidlow C, Smith GR, Fairburn J, Armitage CJ, Stephansen H, Speight S (2009) Small area and individual level predictors of physical activity in urban communities: a multi-level study in Stoke-on-Trent, England. Int J Environ Res Public Health 6:654-677

Dadvand P, de Nazelle A, Figueras F, Basagaña X, Jason S, Amoly E, Jerrett M, Vrijheid M, Sunyer J, Nieuwenhuijsen MJ (2012) Green space, health inequality and pregnancy. Environ Int 40(April): 110-115

Dadvand P, Villanueva CM, Font-Ribera L, Martinez D, Basagana X, Belmonte J, Vrijheid M, Grazuleviciene R, Kogevinas M, Nieuwenhuijsen MJ (2014a) Risks and benefits of green spaces for children: a cross-sectional study of associations with sedentary behavior, obesity, asthma, and allergy. Environ Health Perspect 122:1329-1335

Dadvand P, Wright J, Martinez D, Basagaña X, Mceachan RRC, Cirach M, Gidlow CJ, De Hoogh K, Gražulevičienė R, Nieuwenhuijsen MJ (2014b) Inequality, green spaces, and pregnant women: roles of ethnicity and individual and neighbourhood socioeconomic status. Environ Int 71:101-108

Dadvand P, Nieuwenhuijsen MJ, Esnaola M, Forns J, Basagana X, Alvarez-Pedrerol M, Rivas I, Lopez-Vicente M, De Castro Pascual M, Su J, Jerrett M, Querol X, Sunyer J (2015) Green spaces and cognitive development in primary schoolchildren. Proc Natl Acad Sci U S A 112:7937-7942

De Jong K, Albin M, Skärbäck E, Grahn P, Björk J (2012) Perceived green qualities were associated with neighborhood satisfaction, physical activity, and general health: results from a crosssectional study in suburban and rural Scania, southern Sweden. Health Place 18:1374-1380

De Vries S (2010) Nearby nature and human health: looking at the mechanisms and their implications. In: Ward Thompson C, Aspinall P, Bell S (eds) Innovative approaches to researching landscape and health. Routledge, Abingdon

De Vries S, Van Dillen SME, Groenewegen PP, Spreeuwenberg P (2013) Streetscape greenery and health: stress, social cohesion and physical activity as mediators. Soc Sci Med 94:26-33

Dzhambov AM, Dimitrova DD, Dimitrakova ED (2014) Association between residential greenness and birth weight: systematic review and meta-analysis. Urban For Urban Green 13:621-629

Epstein LH, Raja S, Gold SS, Paluch RA, Pak Y, Roemmich JN (2006) Reducing sedentary behavior: the relationship between park area and the physical activity of youth. Psychol Sci 17:654-659

European Environment Agency (2015) SOER 2015 - The European environment — state and outlook 2015. Urban systems briefing, Copenhagen. http://www.eea.europa.eu/soer-2015/europe/ urban-systems\#tab-based-on-indicators. Accessed 13 May 2016

Faber Taylor A, Kuo FE (2006) Is contact with nature important for healthy child development? State of the evidence. In: Spencer C, Blades M (eds) Children and their environments: learning, using and designing spaces. Cambridge University Press, Cambridge, pp 124-140

Faber Taylor AF, Kuo FEM (2011) Could exposure to everyday green spaces help treat ADHD? Evidence from children's play settings. Appl Psychol Health Well-Bring 3:281-303

Fuertes E, Markevych I, Bowatte G, Gruzieva O, Gehring U, Becker A, Berdel D, von Berg A, Bergström A, Brauer M, Brunekreef B, Brüske I, Carlsten C, Chan-Yeung M, Dharmage SC, Hoffmann B, Klümper C, Koppelman GH, Kozyrskyj A, Korek M, Kull I, Lodge C, Lowe A, MacIntyre E, Pershagen G, Standl M, Sugiri D, Wijga A, Heinrich J (2016) Residential greenness is differentially associated with childhood allergic rhinitis and aeroallergen sensitization in seven birth cohorts. Allergy. doi:10.1111/all.12915. [Epub ahead of print] 
Gardsjord HS, Tveit MS, Nordh H (2014) Promoting youth's physical activity through park design: linking theory and practice in a public health perspective. Landsc Res 39:70-81

Gascon M, Triguero-Mas M, Martínez D, Dadvand P, Rojas-Rueda D, Plasència A, Nieuwenhuijsen MJ (2016) Residential green spaces and mortality: a systematic review. Environ Int 86:60-67

Gidlow CJ, Jones MV, Hurst G, Masterson D, Clark-Carter D, Tarvainen MP, Smith G, Nieuwenhuijsen M (2016a) Where to put your best foot forward: psycho-physiological responses to walking in natural and urban environments. J Environ Psychol 45:22-29

Gidlow CJ, Randall J, Gillman J, Smith GR, Jones MV (2016b) Natural environments and chronic stress measured by hair cortisol. Landsc Urban Plan 148:61-67

Grazuleviciene R, Danileviciute A, Dedele A, Vencloviene J, Andrusaityte S, Uzdanaviciute I, Nieuwenhuijsen MJ (2015a) Surrounding greenness, proximity to city parks and pregnancy outcomes in Kaunas cohort study. Int J Hyg Environ Health 218:358-365

Grazuleviciene R, Vencloviene J, Kubilius R, Grizas V, Dedele A, Grazulevicius T, Ceponiene I, Tamuleviciute-Prasciene E, Nieuwenhuijsen MJ, Jones M, Gidlow C (2015b) The effect of park and urban environments on coronary artery disease patients: a randomized trial. Biomed Res Int 2015:9

Hanski I, von Hertzen L, Fyhrquist N, Koskinen K, Torppa K, Laatikainen T, Karisola P, Auvinen P, Paulin L, Mäkelä MJ, Vartiainen E, Kosunen TU, Alenius H, Haahtela T (2012) Environmental biodiversity, human microbiota, and allergy are interrelated. Proc Natl Acad Sci U S A 109:8334-8339

Hartig T (2007) Three steps to understanding restorative environments as health resources. In: Thompson CW, Travlou P (eds) Open space: people space. Taylor \& Francis, Abingdon

Hartig T, Mitchell R, De Vries S, Frumkin H (2014) Nature and health. Annu Rev Public Health 35:207-228

Honold J, Lakes T, Beyer R, Van Der Meer E (2015) Restoration in urban spaces: nature views from home, greenways, and public parks. Environ Behav 48(6):796-825

Hu Z, Liebens J, Rao KR (2008) Linking stroke mortality with air pollution, income, and greenness in Northwest Florida: an ecological geographical study. Int J Health Geogr 7:20

James P, Banay RF, Hart JE, Laden F (2015) A review of the health benefits of greenness. Curr Epidemiol Rep 2:131-142

Kaczynski AT, Henderson KA (2007) Environmental correlates of physical activity: a review of evidence about parks and recreation. Leis Sci 29:315-354

Kaczynski AT, Potwarka LR, Saelens BE (2008) Association of park size, distance, and features with physical activity in neighborhood parks. Am J Public Health 98:1451-1456

Kaplan S (1995) The restorative benefits of nature: toward an integrative framework. J Environ Psychol 15:169-182

Kaplan S (2001) Meditation, restoration, and the Management of Mental Fatigue. Environ Behav 33(4):480-506

Kihal-Talantikite et al (2013) Green space, social inequalities and neonatal mortality in France. BMC Pregnancy Childbirth 13:191

Kim J, Kaplan R (2004) Physical and psychological factors in sense of community: new urbanist kentlands and nearby orchard village. Environ Behav 36:313-340

Kondrashova A, Seiskari T, Ilonen J, Knip M, Hyöty H (2013) The 'hygiene hypothesis' and the sharp gradient in the incidence of autoimmune and allergic diseases between Russian Karelia and Finland. APMIS 121(6):478-493

Kuo M (2015) How might contact with nature promote human health? Promising mechanisms and a possible central pathway. Front Psychol 25:1093

Lachowycz K, Jones AP (2011) Greenspace and obesity: a systematic review of the evidence. Obes Rev 12:e183-e189

Lachowycz K, Jones AP (2013) Towards a better understanding of the relationship between greenspace and health: development of a theoretical framework. Landsc Urban Plan 118:62-69 
Lachowycz K, Jones AP (2014) Does walking explain associations between access to greenspace and lower mortality? Soc Sci Med 107:9-17

Lachowycz K, Jones AP, Page AS, Wheeler BW, Cooper AR (2012) What can global positioning systems tell us about the contribution of different types of urban greenspace to children's physical activity? Health Place 18:586-594

Laurent O, Wu J, Li L, Milesi C (2013) Green spaces and pregnancy outcomes in Southern California. Health Place 24:190-195

Lengen C, Kistemann T (2012) Sense of place and place identity: review of neuroscientific evidence. Health Place 18(5):1162-1171

Li Q, Morimoto K, Kobayashi M, Inagaki H, Katsumata M, Hirata Y, Hirata K, Suzuki H, Li Y, Wakayama Y (2008) Visiting a forest, but not a city, increases human natural killer activity and expression of anti-cancer proteins. Int J Immunopathol Pharmacol 21:117-127

Logan AC (2015) Dysbiotic drift: mental health, environmental grey space, and microbiota. J Physiol Anthropol 34:23

Lõhmus M, Balbus J (2015) Making green infrastructure healthier infrastructure. Infect Ecol Epidemiol 2015:30082

Lovasi GS, Quinn JW, Neckerman KM, Perzanowski MS, Rundle A (2008) Children living in areas with more street trees have lower asthma prevalence. J Epidemiol Community Health 62:647-649

Lynch SV, Wood RA, Boushey H, Bacharier LB, Bloomberg GR, Kattan M, O'connor GT, Sandel MT, Calatroni A, Matsui E, Johnson CC, Lynn H, Visness CM, Jaffee KF, Gergen PJ, Gold DR, Wright RJ, Fujimura K, Rauch M, Busse WW, Gern JE (2014) Effects of early-life exposure to allergens and bacteria on recurrent wheeze and atopy in urban children. J Allergy Clin Immunol 134:593-601. e12

Maas J, Van Dillen SME, Verheij RA, Groenewegen PP (2009a) Social contacts as a possible mechanism behind the relation between green space and health. Health Place 15:586-595

Maas J, Verheij RA, De Vries S, Spreeuwenberg P, Schellevis FG, Groenewegen PP (2009b) Morbidity is related to a green living environment. J Epidemiol Community Health 63:967-973

Markevych I, Fuertes E, Tiesler CM, Birk M, Bauer CP, Koletzko S, Von Berg A, Berdel D, Heinrich J (2014) Surrounding greenness and birth weight: results from the GINIplus and LISAplus birth cohorts in Munich. Health Place 26:39-46

Mitchell R (2013) Is physical activity in natural environments better for mental health than physical activity in other environments? Soc Sci Med 91:130-134

Mitchell R, Popham F (2007) Greenspace, urbanity and health: relationships in England. J Epidemiol Community Health 61:681-683

Mitchell R, Popham F (2008) Effect of exposure to natural environment on health inequalities: an observational population study. Lancet 372:1655-1560

Mitchell RJ, Richardson EA, Shortt NK, Pearce JR (2015) Neighborhood environments and socioeconomic inequalities in mental well-being. Am J Prev Med 49:80-84

Nieminen T, Martelin T, Koskinen S, Aro H, Alanen E, Hyyppä M (2010) Social capital as a determinant of self-rated health and psychological well-being. Int J Public Health 55:531-542

Owen N, Healy GN, Matthews CE, Dunstan DW (2010) Too much sitting: the population-health science of sedentary behavior. Exerc Sport Sci Rev 38:105-113

Pantell M, Rehkopf D, Jutte D, Syme SL, Balmes J, Adler N (2013) Social isolation: a predictor of mortality comparable to traditional clinical risk factors. Am J Public Health 103:2056-2062

Pereira G, Foster S, Martin K, Christian H, Boruff BJ, Knuiman M, Giles-Corti B (2012) The association between neighborhood greenness and cardiovascular disease: an observational study. BMC Public Health 12:466-466

Pope D, Tisdall R, Middleton J, Verma A, Van Ameijden E, Birt C, Bruce NG (2015) Quality of and access to green space in relation to psychological distress: results from a population-based cross-sectional study as part of the EURO-URHIS 2 project. Eur J Pub Health pii:ckv094. [Epub ahead of print] 
Public Health England (2014) Local action on health inequalities: improving access to green spaces. Public Health England, London

Reklaitiene R, Grazuleviciene R, Dedele A, Virviciute D, Vensloviene J, Tamosiunas A, Baceviciene M, Luksiene D, Sapranaviciute-Zabazlajeva L, Radisauskas R, Bernotiene G, Bobak M, Nieuwenhuijsen MJ (2014) The relationship of green space, depressive symptoms and perceived general health in urban population. Scand J Public Health 42:669-676

Richardson EA, Mitchell R, Hartig T, De Vries S, Astell-Burt T, Frumkin H (2012) Green cities and health: a question of scale? J Epidemiol Community Health 66:160-165

Roe JJ, Thompson CW, Aspinall PA, Brewer MJ, Duff EI, Miller D, Mitchell R, Clow A (2013) Green space and stress: evidence from cortisol measures in deprived urban communities. Int J Environ Res Public Health 10:4086-4103

Roe J, Aspinall P (2011) The restorative benefits of walking in urban and rural settings in adults with good and poor mental health. Health Place 17:103-113

Rook G (2013) Regulation of the immune system by biodiversity from the natural environment: an ecosystem service essential to health. Proc Natl Acad Sci U S A 110:18360-18367

Ruokolainen L, von Hertzen L, Fyhrquist N, Laatikainen T, Lehtomäki J, Auvinen P, Karvonen AM, Hyvärinen A, Tillmann V, Niemelä O, Knip M, Haahtela T, Pekkanen J, Hanski I (2015) Green areas around homes reduce atopic sensitization in children. Allergy 70:195-202

Sallis JF et al (2016) Physical activity in relation to urban environments in 14 cities worldwide: a cross-sectional study. Lancet 387:2207-2217

Schipperijn J, Bentsen P, Troelsen J, Toftager M, Stigsdotter UK (2013) Associations between physical activity and characteristics of urban green space. Urban For Urban Green 12:109-116

Seeland K, Dübendorfer S, Hansmann R (2009) Making friends in Zurich's urban forests and parks: the role of public green space for social inclusion of youths from different cultures. Forest Policy Econ 11:10-17

Shanahan DF, Lin BB, Bush R, Gaston KJ, Dean JH, Barber E, Fuller RA (2015) Toward improved public health outcomes from urban nature. Am J Public Health 105(3):470-477

Sreetheran M, Van Den Bosch CCK (2014) A socio-ecological exploration of fear of crime in urban green spaces - a systematic review. Urban For Urban Green 13:1-18

Sugiyama T, Ward Thompson C (2008) Associations between characteristics of neighbourhood open space and older people's walking. Urban For Urban Green 7:41-51

Sugiyama T, Leslie E, Giles-Corti B, Owen N (2008) Associations of neighbourhood greenness with physical and mental health: do walking, social coherence and local social interaction explain the relationships? J Epidemiol Community Health 62:e9

Sugiyama T, Cerin E, Owen N, Oyeyemi AL, Conway TL, Van Dyck D, Schipperijn J, Macfarlane DJ, Salvo D, Reis RS, Mitáš J, Sarmiento OL, Davey R, Schofield G, Orzanco-Garralda R, Sallis JF (2014) Perceived neighbourhood environmental attributes associated with adults recreational walking: IPEN adult study in 12 countries. Health Place 28:22-30

Takano T, Nakamura K, Watanabe M (2002) Urban residential environments and senior citizens' longevity in megacity areas: the importance of walkable green spaces. J Epidemiol Community Health 56:913-918

Tamosiunas A, Grazuleviciene R, Luksiene D, Dedele A, Reklaitiene R, Baceviciene M, Vencloviene J, Bernotiene G, Radisauskas R, Malinauskiene V, Milinaviciene E, Bobak M, Peasey A, Nieuwenhuijsen MJ (2014) Accessibility and use of urban green spaces, and cardiovascular health: findings from a Kaunas cohort study. Environ Health 13:20

The Marmot Review (2010) Fair society, healthy lives: strategic review of health inequalities in England post-2010. UCL IHE, London

Thiering E, Markevych I, Brüske I, Fuertes E, Kratzsch J, Sugiri D, Hoffmann B, Von Berg A, Bauer CP, Koletzko S, Berdel D, Heinrich J (2016) Associations of residential long-term air pollution exposures and satellite-derived greenness with insulin resistance in German adolescents. Environ Health Perspect 124(8):1291-1298. [Epub ahead of print] 
Triguero-Mas M, Dadvand P, Cirach M, Martínez D, Medina A, Mompart A, Basagaña X, Gražulevičienė R, Nieuwenhuijsen MJ (2015) Natural outdoor environments and mental and physical health: relationships and mechanisms. Environ Int 77:35-41

Ulrich RS (1983) Aesthetic and affective response to natural environment. In: Altman I, Wohlwill $\mathrm{JF}$ (eds) Human behavior \& environment: advances in theory \& research. Plenum, New York

Ulrich RS, Simons RF, Losito BD, Fiorito E, Miles MA, Zelson M (1991) Stress recovery during exposure to natural and urban environments. J Environ Psychol 11:201-230

United Nations (2016) Sustainable development goals and related targets, New York. https://sustainabledevelopment.un.org/topics. Accessed 13 May 2016

Van Den Berg AE, Custers MHG (2011) Gardening promotes neuroendocrine and affective restoration from stress. J Health Psychol 16:3-11

Van Den Berg AE, Van Den Berg CG (2011) A comparison of children with ADHD in a natural and built setting. Child Care Health Dev 37:430-439

Van Den Berg M, Van Poppel M, Van Kamp I, Andrusaityte S, Balseviciene B, Cirach M, Danileviciute A, Ellis N, Hurst G, Masterson D, Smith G, Triguero-Mas M, Uzdanaviciute I, Wit PD, Mechelen WV, Gidlow C, Grazuleviciene R, Nieuwenhuijsen MJ, Kruize H, Maas J (2016) Visiting green space is associated with mental health and vitality: a cross-sectional study in four European cities. Health Place 38:8-15

Van Den Bosch MA, Ostergren PO, Grahn P, Skarback E, Wahrborg P (2015) Moving to serene nature may prevent poor mental health - results from a Swedish longitudinal cohort study. Int J Environ Res Public Health 12:7974-7989

Villeneuve PJ, Jerrett M, Su JG, Burnett RT, Chen H, Wheeler AJ, Goldberg MS (2012) A cohort study relating urban green space with mortality in Ontario, Canada. Environ Res 115(63):5158. doi:10.1016/j.envres.2012.03.003

Villanueva K, Badland H, Hooper P, Koohsari MJ, Mavoa S, Davern M, Roberts R, Goldfeld S, Giles-Corti B (2015) Developing indicators of public open space to promote health and wellbeing in communities. Appl Geogr 57:112-119

Völker S, Kistemann T (2015) Developing the urban blue: comparative health responses to blue and green urban open spaces in Germany. Health Place 35:196-205

Ward Thompson C, Roe J, Aspinall P, Mitchell R, Clow A, Miller D (2012) More green space is linked to less stress in deprived communities: evidence from salivary cortisol patterns. Landsc Urban Plan 105:221-229

Ward Thompson C, Roe J, Aspinall P (2013) Woodland improvements in deprived urban communities: what impact do they have on people's activities and quality of life? Landsc Urban Plan 118:79-89

Ward Thompson C, Aspinall P, Roe J, Robertson L, Miller D (2016) Mitigating stress and supporting health in deprived urban communities: the importance of green space and the social environment. Int J Environ Res Public Health 13:440

White MP, Alcock I, Wheeler BW, Depledge MH (2013) Would you be happier living in a greener urban area? A fixed-effects analysis of panel data. Psychol Sci 24:920-928

Wilker EH, Wu C-D, Mcneely E, Mostofsky E, Spengler J, Wellenius GA, Mittleman MA (2014) Green space and mortality following ischemic stroke. Environ Res 133:42-48

WHO Regional Office for Europe (2010) Parma declaration and commitment to act, Copenhagen. http://www.euro.who.int/_data/assets/pdf_file/0011/78608/E93618.pdf. Accessed 13 May 2016

WHO Regional Office for Europe (2012) Addressing the social determinants of health: the urban dimension and the role of local government. World Health Organization, Geneva

WHO Regional Office for Europe (2013) Health 2020. A European policy framework and strategy for the 21stcentury, Copenhagen, http://www.euro.who.int/_data/assets/pdf_file/0011/199532/ Health2020-Long.pdf?ua=1. Accessed 13 May 2016

WHO Regional Office for Europe (2014) Obesity and inequities. Guidance for addressing inequities in overweight and obesity. Copenhagen. http://www.euro.who.int/_data/assets/pdf_ file/0003/247638/obesity-090514.pdf?ua=1. Accessed 13 May 2016 
WHO Regional Office for Europe (2016) Urban green spaces and health. WHO Regional Office for Europe, Copenhagen

WHO Regional Office for Europe (2017) Urban green space interventions and health. A review of impacts and effectiveness. WHO Regional Office for Europe, Copenhagen

Xu Y, Dadvand P, Barrera-Gómez J, Sartini C, Marí-Dell'olmo M, Borrell C, Medina-Ramón M, Sunyer J, Basagaña X (2013) Differences on the effect of heat waves on mortality by sociodemographic and urban landscape characteristics. J Epidemiol Community Health 67:519-525

Yang CY, Boen C, Gerken K, Li T, Schorpp K, Harris KM (2016) Social relationships and physiological determinants of longevity across the human life span. Proc Natl Acad Sci U S A 113:578-583

Open Access This chapter is licensed under the terms of the Creative Commons Attribution 4.0 International License (http://creativecommons.org/licenses/by/4.0/), which permits use, sharing, adaptation, distribution and reproduction in any medium or format, as long as you give appropriate credit to the original author(s) and the source, provide a link to the Creative Commons license and indicate if changes were made.

The images or other third party material in this chapter are included in the chapter's Creative Commons license, unless indicated otherwise in a credit line to the material. If material is not included in the chapter's Creative Commons license and your intended use is not permitted by statutory regulation or exceeds the permitted use, you will need to obtain permission directly from the copyright holder. 